\title{
dossier
}

\section{De Juan Ambrosio Huerta a Mariano Holguín: episcopado, ultramontanismo y modernidad en Arequipa (1880-1935)*}

\author{
Rolando IBERICO RUIZ \\ Pontificia Universidad Católica del Perú (Lima, Perú) \\ ribericor@pucp.pe
}

Código ORCID: 0000-0003-2967-4036

\section{RESUMEN}

En el Perú, ante el avance de sectores liberales en Lima, Arequipa se constituyó como una ciudad baluarte del catolicismo. En este proceso, el episcopado jugó un papel clave como dinamizador de espacios de formación ultramontana para el clero y el laicado, de promoción de sociedades laicales apologéticas y sociales, de consolidación de prácticas piadosas y de construcción de una legitimidad pública para la Iglesia en la ciudad. En este sentido, este artículo estudia el proceso de afianzamiento del ultramontanismo y del catolicismo social de los episcopados de José Ambrosio Huerta, Manuel Ballón y Mariano Holguín. De 
esta manera, la Iglesia fortaleció su presencia en el espacio público regional y pudo articular un discurso sobre la modernidad desde la perspectiva católica, a favor de la presencia pública de la Iglesia como estructuradora de la vida política, social y moral en la ciudad.

Palabras clave: ultramontanismo, Arequipa, José Ambrosio Huerta, Manuel Ballón, Mariano Holguín

\title{
From Juan Ambrosio Huerta to Mariano Holguín: episcopacy, ultra- montanism and modernity in Arequipa (1880-1930)
}

\begin{abstract}
In Peru, while the liberal sectors in Lima were gaining presence, Arequipa became a bastion city of Catholicism. In this process, the episcopacy played a key role as a catalyst of spaces of ultramontane formation for the clergy and the laity, of promotion of lay apologetic and social societies, of consolidation of pious practices and of construction of public legitimacy for the Church in the city. In this sense, this article studies the consolidation process of ultramontanism and social Catholicism among the episcopates of José Ambrosio Huerta, Manuel Ballón and Mariano Holguín. Hence, the Church strengthened its presence in the regional public space and was able to articulate discourse on modernity from the Catholic perspective, in favor of the public presence of the Church as the structuring of political, social and moral life in the city.
\end{abstract}

KeYwords: ultramontanism, Arequipa, José Ambrosio Huerta, Manuel Ballón, Mariano Holguín

* Este trabajo fue financiado por la Dirección de Gestión de la Investigación de la Pontificia Universidad Católica del Perú, a través de la subvención DGI 2016-1-0037 para el proyecto «Una ciudad de Dios en el Perú: la formación de la Arequipa católica, 1856-1925». 


\section{INTRODUCCIÓN}

LA RESTAURACIÓN DE LA JERARQUía ECLESIÁSTICA en América Latina desde la década de 1840 y la imposición del ultramontanismo en las estructuras institucionales de la Iglesia acercaron a los obispos a Roma y produjeron una convergencia teológica para comprender las amenazas que enfrentaba la Iglesia universal en el borrascoso mar del siglo (Klaiber 1988: 100; Iberico 2013). En el Perú, los vínculos de la Iglesia con el papado se estrecharon a lo largo del siglo XIX. Primero, la misión de Bartolomé Herrera para obtener un concordato con la Sede Apostólica en 1852, ${ }^{1}$ si bien como representante del Estado peruano, produjo en Herrera una conversión al ultramontanismo. Incluso desde Roma, Herrera compró una imprenta que sirvió para las batallas ideológicas contra el liberalismo y el catolicismo regalista de la segunda mitad de la década (Iberico 2013: 52). Además, en la segunda mitad del siglo XIX, tres obispos peruanos, Ezequiel Moreyra, Juan Ambrosio Huerta y Teodoro del Valle —obispos de Ayacucho, Puno y Huánuco, respectivamenteestuvieron presentes en el Concilio Vaticano I (1869-1870) convocado por Pío IX, en el cual se declaró el dogma de la infalibilidad pontificia. Es decir, desde mediados del siglo XIX, el papado inició una política de «romanización» del episcopado latinoamericano que fortaleció el papel doctrinal, jurídico y espiritual del pontífice en lugar de la noción de Iglesias «nacionales», propias del modelo eclesial galicano y regalista del siglo XVIII. Además, este proceso afirmó la autoridad espiritual del papa sobre las Iglesias locales y favoreció la construcción de una autoridad supranacional para las Iglesias que prescindía del patronato estatal (Cárdenas 2018: 105-107).

En este proceso de «romanización», los obispos tuvieron un papel central en el fortalecimiento de la autoridad doctrinal, jurídica y espiritual de Roma. Este proceso iba de la mano con la promoción

\footnotetext{
1 Sobre la misión de Bartolomé Herrera en 1852, consultar Iannettone (2003).
} 
del ultramontanismo, que era un conjunto de ideas teológico-políticas que defendían la absoluta autoridad del papa sobre las Iglesias locales y se oponían a la interferencia estatal en asuntos eclesiales. Además, los ultramontanos afirmaban la autoridad doctrinal de la Iglesia sobre el Estado en diversos asuntos políticos como la confesionalidad del Estado. Los ultramontanos promovieron la unidad dogmática y jurídica de la Iglesia y del papado, que garantizaba la independencia de las Iglesias locales (Iberico 2013: 5). Acompañaron a las ideas ultramontanas un conjunto de símbolos y prácticas creadores de una sólida identidad católica. Estos fueron la devoción al papa, la asistencia a la misa como distintivo en una sociedad en proceso de secularización, la primacía del clero como único representante de la Iglesia en la sociedad secular, la práctica de devociones como el Sagrado Corazón de Jesús, la celebración de los jubileos papales y episcopales, y el resurgimiento de la práctica de los retiros y ejercicios espirituales (Anderson 2000: 32). De esta manera, se construyó un «nuevo catolicismo» como parte de la institucionalización de la Iglesia y del resurgimiento que conllevó, como respuesta al creciente proceso secularizador del Estado y la sociedad. Este proceso, liderado por los obispos y el clero, se tiñó de una vehemente retórica contra los «enemigos» del catolicismo e involucró activamente a los laicos y laicas en la defensa y promoción del catolicismo, mediante el uso de la prensa y otros medios modernos como las asociaciones (Clark 2003: 11).

En Arequipa, los obispos jugaron un rol central en la configuración institucional y en la dirección política y pastoral que tuvo la Iglesia local, especialmente con los obispos de las décadas finales del XIX y las primeras del XX. Los prelados arequipeños, desde la segunda mitad del siglo XIX, fueron artífices de la creación de este «nuevo catolicismo», a través de sus cartas pastorales y la política eclesial que sostuvieron durante sus pontificados. Los obispos del periodo anterior al presente estudio, Bartolomé Herrera Vélez (1860-1864), Juan Calienes (1865-1866) y José Benedicto Torres 
(1868-1880), corresponden a la primera etapa de la romanización, cuya finalidad fue la formación ultramontana del clero, la reforma de las estructuras eclesiales, de acuerdo con las estructuras eclesiales romanas, ${ }^{2}$ y la apropiación del discurso antimoderno del papado de Pío IX. No obstante, los intentos de reforma educativa de los planes formativos del Seminario de San Jerónimo no se implementaron adecuadamente por la brevedad de los gobiernos de Herrera Vélez y Calienes. Además, la Guerra del Pacífico (1879-1883) cambió las prioridades de la Iglesia para atender la situación de emergencia del país (Iberico 2017: 17-48). No obstante, la Iglesia arequipeña constituye un ejemplo de recepción del ultramontanismo internacional y del resurgimiento católico sustentado en un intenso activismo de las sociedades laicales. La constitución de una progresiva pluralidad política en el Perú, con la presencia de grupos liberales, socialistas, entre otros, obligó a sectores de la Iglesia a redescubrir el espacio público a través de las sociedades laicales y el soporte eclesial. Sin renunciar a la intención de monopolizar el espacio público, la Iglesia aprendió a convivir en la esfera pública y a reconocer su complejidad, en un claro proceso de incipiente «modernización» (Iberico 2017).

El periodo de estudio, que se podría denominar como «el segundo momento de la romanización», contó con la presencia de importantes prelados, quienes reforzaron el ultramontanismo no solo en el clero, sino también entre los laicos. Este segundo momento contó con la activa presencia de sociedades laicales que fueron involucradas —en el esquema jerárquico de sumisión del laicado al clero- en las actividades eclesiales. Los obispos estudiados tuvieron espacios para conocer la romanité, como decía Pío XI. Es decir, en

2 Como ejemplo de la reforma de las costumbres eclesiales, entre 1856 y 1858, el Cabildo Metropolitano de la Catedral de Lima, al que pertenecía como chantre Bartolomé Herrera, realizó una reforma de las vestiduras litúrgicas según la normativa romana de la basílica de San Juan de Letrán. El encargado del proceso de aclaración de los colores, modelos y usanza de la nueva vestidura litúrgica fue Bartolomé Herrera (Iberico 2013: 109-111). 
Roma era posible conocer lo que «es verdaderamente la perfección de la catolicidad» (citado en Fouilloux 1998: 45). Juan Ambrosio Huerta, obispo entre 1880 y 1897, participó en el espacio católico global más importante del siglo XIX ultramontano, el Concilio Vaticano I. Por su parte, Manuel Ballón, obispo entre 1898 y 1906, fue invitado al Concilio Plenario Latinoamericano, convocado por León XIII y celebrado en Roma en 1899, y en el que se consagró el continente latinoamericano al Corazón de Jesús. Finalmente, Mariano Holguín, obispo entre 1906 y 1945, antes de su consagración episcopal participó como franciscano en el Capítulo General de su orden, celebrado en Roma en 1903. Estas circunstancias permitieron a estos personajes apropiarse del discurso pontificio, de la problemática eclesial desde la perspectiva de Roma, y del repertorio cultural católico, con un fuerte énfasis en la devoción papal y el discurso antimoderno. Con la fuerza y el prestigio de la globalidad católica que otorgaba el papado, estos obispos asumieron una fuerte consciencia eclesial e implicaron en este proceso a laicos y laicas, quienes compartieron esta consciencia eclesial global en sus organizaciones con la finalidad de fortalecer la presencia pública de la Iglesia en Arequipa.

La romanización de la Iglesia en Arequipa se dio en pleno proceso de modernización de la ciudad y la región, gracias a la inserción relativamente rápida del comercio lanero en el mercado internacional. El proceso de recuperación económica, tras la debacle producida por la guerra con Chile, se vinculó con el fortalecimiento de la identidad regional y católica de la ciudad. La catolicidad de la ciudad fue una de las principales características destacadas por los obispos y, en 1895, miembros de la élite arequipeña colaboraron con Nicolás de Piérola y el Partido Demócrata para la obtención del poder central en Lima. En medio de ayunos, procesiones y sermones de la Semana Santa, Piérola y los notables arequipeños mostraron la catolicidad política de la ciudad frente a la ambigua y liberal Lima (Carpio 1990: 546). Sin embargo, el ambiente católico de la ciudad 
no impidió el surgimiento del movimiento liberal, especialmente con la fundación del Partido Liberal Independiente, y la presencia de grupos protestantes. Ambas situaciones introdujeron un reto a la Iglesia arequipeña y moldeó el debate político, la actitud del episcopado y de las asociaciones católicas en el espacio público. En este sentido, el discurso antimoderno debe ser complejizado, pues los católicos emplearon formas políticas modernas como partidos políticos, mítines, prensa y revueltas (Ivereigh 2000: 12-13). Además, las asociaciones laicales abrieron el espacio público como una nueva arena de disputa y negociación con las nuevas ideas políticas. De esta manera, no se puede denominar como absolutamente antimoderno al catolicismo preconciliar, pues existieron medios y espacios para el «compromiso» y el reconocimiento progresivo de la pluralidad del espacio público.

El estudio de los cambios en el lenguaje episcopal y la práctica pastoral de los episcopados de Juan Ambrosio Huerta, Manuel Ballón y Mariano Holguín, permite comprender la recepción y adaptación local de las ideas pontificias, el «compromiso» ${ }^{3}$ con la modernidad emergente en Arequipa desde fines del siglo XIX y la construcción de los enemigos del catolicismo arequipeño. En este sentido, se puede analizar los progresivos cambios desde la intransigencia propia de la retórica ultramontana del pontificado de Pío IX hasta la ambivalente apertura del catolicismo al espacio público y la sociedad promovida por León XIII. En el caso de Arequipa, la recepción de ese proceso se produjo de diversas maneras en los tres episcopados tratados en este texto. En cada uno de ellos se revela diversas formas de recepción del magisterio pontificio y las adaptaciones al contexto cambiante de Arequipa desde finales del siglo XIX hasta las primeras décadas del siglo XX. En este sentido,

3 El concepto «compromiso» (engagement) permite comprender la relación compleja con la modernidad a través de la acomodación, la ambivalencia e, incluso, el rechazo rotundo (Wright-Rios 2009: 26). 
el estudio se mueve desde el año de inicio del gobierno episcopal de Juan Ambrosio Huerta, 1880, hasta 1935, año de la fundación de la Acción Católica Peruana, que es el cierre de una etapa de activismo episcopal y laical en Arequipa. Finalmente, la relación del catolicismo arequipeño con la creciente modernidad se movió entre el total rechazo en el plano discursivo, como dan cuentan las cartas pastorales de Huerta y Ballón, hasta la relación ambivalente y negociadora en el espacio público y político, escenario de disputa con otros actores políticos y sociales, que caracterizó el episcopado de Holguín. En este estudio se aborda este proceso histórico desde el análisis de las trayectorias y el magisterio episcopal de los tres prelados arequipeños.

\section{El obispo Juan Ambrosio Huerta: un auténtico ultramonta- No (1880-1897)}

Juan Ambrosio Huerta Galván nació en Lima el 7 de diciembre de 1823. Se educó en el Seminario de Santo Toribio, del que fue nombrado vicerrector en 1847. Durante ese año participó activamente, junto al arzobispo metropolitano Francisco Javier de Luna Pizarro, en la reforma del plan de estudios del seminario y la renovación de la biblioteca con diversos autores ultramontanos como Joseph De Maistre (Iberico 2013: 46). Su temprano ultramontanismo lo hizo cercano a otros presbíteros afines como Bartolomé Herrera y Pedro José Tordoya, con quienes combatió activamente el reformismo liberal de la Convención Nacional de 1855 y los rezagos del catolicismo regalista. Llegó a ser el editor del periódico ultramontano El Católico (1855-1860), publicado en el Seminario de Santo Toribio del que era vicerrector, y en cuyas páginas se opuso a los liberales-regalistas y defendió activamente las prerrogativas y la autoridad absoluta de la Sede Apostólica sobre la Iglesia peruana, así como la autonomía de la Iglesia 
respecto del Estado. Con el final del ciclo reformista liberal y la consolidación del ultramontanismo, en 1861 fue nombrado rector del Seminario de Santo Toribio e incorporado como canónigo al Cabildo Metropolitano de la Catedral de Lima. La fama de Huerta, de sacerdote celoso y destacado orador sagrado, pareció hacerlo idóneo para el episcopado; al que fue propuesto en 1864 por el presidente del Perú Juan Antonio Pezet para la sede de Puno. En 1865 fue preconizado por Pío IX.

Desde Lima, como obispo de Puno, envió su primera carta pastoral el 9 de julio de 1865. La carta esbozó sus grandes preocupaciones como obispo ultramontano, pues se propuso fundar un seminario en su diócesis y realizar una visita pastoral; además, exigió a los párrocos dar un buen ejemplo, y a los padres y las madres de familia que llevasen a sus hijos a «las explicaciones del Catecismo» (Huerta 1865: 102-107). Solicitaba al clero y sus fieles estar atentos contra «ese diluvio de absurdos que todos los días se publican y circulan contra la religión y contra la sociedad» y que, junto al protestantismo y los errores modernos, amenazan la «civilización cristiana» (Huerta 1865: 108-109). Durante su gobierno, Huerta creó el seminario diocesano, restauró la catedral y fundó el periódico La Iglesia puneña (Fernández 2000: 382). Las tres eran claramente las preocupaciones ultramontanas: la formación del clero, el cuidado de la liturgia y la consolidación de la presencia católica. En 1868 Huerta convocó al primer sínodo diocesano, y en 1869 viajó a Roma para asistir al Concilio Vaticano I, en cuyas sesiones se aprobó el dogma de la infalibilidad pontificia (Martínez 1933: 270). ${ }^{4}$ A su regreso al Perú, pleno del espíritu ul-

4 La constitución dogmática Pastor Aeternus se promulgó el 18 de julio de 1870, tras intensos debates en el aula conciliar y la prensa católica europea. Se aprobó con el voto de 533 de los 535 padres conciliares asistentes. Unos días antes, 55 obispos decidieron retornar a sus países para evitar oponerse públicamente a la mayoría. Sobre los debates teológicos y la votación conciliar, consultar Jedin (1960: 141-150). 
tramontano y más prorromano que nunca, se enfrentó al gobierno de Manuel Pardo que desconoció la autoridad del sínodo romano y la publicación de sus constituciones, por no solicitar el exequatur, es decir, el permiso estatal. Además se enfrentó al Fiscal de la Nación, José Gregorio Paz Soldán, un antiguo regalista, quien lo acusó de no solicitar la autorización necesaria al gobierno para asistir al Concilio (Klaiber 1988: 137). El conflicto se prolongó hasta 1874, año en que el papa Pío IX aceptó la renuncia de Huerta al obispado, enviada a través del Delegado Apostólico Serafino Vannutelli. ${ }^{5}$ Acorde con su espíritu ultramontano, renunció sin informar al gobierno. ${ }^{6}$

Para Klaiber (1988), la renuncia del obispo es un ejemplo de la autoridad del Estado sobre la Iglesia; sin embargo, la actitud de Huerta muestra el compromiso ultramontano de defender la independencia jurídica de los asuntos internos de la Iglesia, incluso a costa de perder el episcopado. La fidelidad a la institución estaba sobre cualquier otro compromiso personal y la defensa de la Iglesia y del papado era hasta entregar la vida. La fama del renunciante prelado resonó más allá del país, pues el ultramontano presidente de Ecuador, Gabriel García Moreno, le ofreció el deanato de la Catedral de Quito; pero Huerta decidió permanecer como cura en Huacho, primero, y luego como párroco en Santa Ana, en Lima (Martínez 1933: 272). Sin embargo, Nicolás de Piérola, un reconocido político católico de Arequipa, lo presentó al obispado de su provincia en 1880. Luego de la confirmación por León XIII, Huerta envió una carta pastoral donde señalaba que «entre las diócesis del Perú, Arequipa ha sido siempre considerada como la más fiel guar-

5 En 1869, el papa Pío IX nombró al arzobispo italiano Seferino Vannutelli como Delegado Apostólico para Ecuador, Perú, Colombia y Centroamérica. En 1871 fue recibido en Lima y en 1875 fue ascendido al puesto de nuncio apostólico en Bruselas, Bélgica.

6 Sobre el conflicto que se desarrolló entre noviembre de 1873 y julio de 1874, consultar Memoria del Ministro de Instrucción, Culto, Justicia y Beneficencia (1874: LXXI-LXXIII, 47-50). 
dadora de la ortodogía [sic], y por lo mismo, como la más escrupulosa en la observancia de los preceptos de la moral cristiana». Por ello, Huerta refería que «el apostolado del infierno, han dicho para sí: "conquistada Arequipa, haciendo entrar a los arequipeños en las vías de nuestro progreso, es nuestra toda la República”» (Huerta 1880: 4-5). La guerra con Chile no impidió que el prelado trazase las líneas centrales de su episcopado, ni lo alejasen de su política ultramontana. Reformó el Seminario de San Jerónimo y lo trasladó de su local colonial, de la calle San Francisco, al desaparecido palacio del Buen Retiro, a espaldas del actual Monasterio de Santa Rosa. Promovió la consagración a los Sagrados Corazones de Jesús y de María y solicitó al clero y los fieles que dieran su beneplácito para la celebración (Huerta 1881: 7-8). Finalmente, consagró la diócesis a los Sagrados Corazones el 30 de agosto de 1881, con la finalidad de, como afirmaba en su pastoral, de salvaguardar la civilización y el progreso en el orden moral (Huerta 1881: 5). En medio de la guerra con Chile, la consagración realizada por el prelado se articuló con los deseos de protección y salvaguarda necesarios en medio del conflicto. Además, ratificaba el carácter católico de la ciudad, destacada por él en su primera pastoral dirigida a su diócesis.

El 1 de marzo de 1883, el prelado convocó a un sínodo en Arequipa, celebrado en septiembre. El objetivo era reorganizar la estructura y la disciplina de la Iglesia católica en Arequipa para poder hacer frente, en palabras del obispo, al «siglo XIX [que] ha tenido la peregrina presunción de llamarse siglo de las luces [...] mejor le vendría el título de SIGLO DE LAS TEAS INCENDIARIAS, teniendo en cuenta que toda su obra se ha reducido a producir un verdadero incendio moral en las sociedades» (Huerta 1883: 10). El «siglo XIX» era el símbolo del mal, del tiempo que amenazaba la barca de Pedro con sus innovaciones ideológicas. En la preocupación ultramontana del obispo, el «siglo XIX» era símbolo del caos moral, de la destrucción del orden y la disolución de la vida humana. De esta manera, Huerta se unía a todo un discurso fatalista sobre la 
historia de la Iglesia, amenazada de ser sujetada y dominada por las «fuerzas del mal». Por ello, en su estructura teológica, la salvación de ese mal radicaba en el sacerdocio, cuyo deplorable estado, señalaba el prelado, se debe «a la falta de ciencia y del espíritu de piedad que sólo puede adquirirse en los Seminarios» (Huerta 1883: 11). Una de las prioridades del sínodo fue la formación educativa y piadosa del clero, pues ello garantizaba la piedad y la moralidad de la sociedad (Huerta 1883: 12). Desde el clero era posible restaurar la vida social y combatir los peligros del inestable siglo XIX. En conjunto, las constituciones expedidas por el sínodo tratan sobre diversos temas relacionados a la administración de la diócesis, de la liturgia, la labor de los párrocos y los programas para predicadores, confesores y futuros ordenados (Constituciones sinodales 1883). Las Constituciones enfatizaron en la sacralidad de la liturgia y de sus administradores, es decir, los presbíteros, sobre quienes se estableció varias normas canónicas, con la finalidad de que sean auténticos modelos de cristianos. El sínodo constituyó parte de las reformas emprendidas por Huerta para ajustarse al modelo católico de piedad romanizadora, clerical y jerárquica.

El impulso ultramontano del obispo Huerta lo llevó a identificar a los enemigos del catolicismo y el peligro que presentaban para la católica Arequipa. En sus cartas pastorales señaló como males centrales de su época la masonería, el racionalismo y el liberalismo; así como la progresiva infiltración de ellas en la sociedad y el gobierno del país. Entre estos perjuicios, el peor de todos era la masonería. Afirmaba el prelado que ella «ha venido trabajando desde la época de nuestra independencia por zapar los cimientos de la Iglesia Católica en nuestra Nación» y ha logrado penetrar en el congreso hasta sancionar la ley de libertad de asociación, que perjudica a las órdenes religiosas (Huerta 1886: 2). Además, continuaba Huerta, se encuentran «a tanta altura en la Capital del Perú», gracias a su «decantada caridad parecida a la que el rico Epulón del Evangelio ostentaba en el fondo del infierno» y «su pa- 
ranoico y criminal anhelo por la educación de la juventud» (Huerta 1886: 2). Ante el «masonismo», Huerta proponía perseverar en las filas de la Iglesia (Huerta 1886: 8). De acuerdo con el prelado, la masonería se encontraba anclada en Lima, ciudad opuesta a la católica Arequipa, y amenazaba la constitución misma de la sociedad nacional. Esta oposición entre Lima y Arequipa se desarrolló en el pensamiento católico ultramontano arequipeño en las décadas siguientes (Iberico 2017: 122).

La oposición a la masonería se legitimaba en la postura pontificia de León XIII, quien condenó y excomulgó a los miembros de las sociedades masónicas en la encíclica Humanum Genus (20 de abril de 1884). La encíclica fue publicada en Arequipa el mismo año, el 1 de agosto. ${ }^{7}$ De la misma forma, el franciscano catalán Elías Passarell publicó La Francmasonería peruana en 1886, en la que realizaba una crítica minuciosa de los ideales masónicos desde la doctrina católica. El epígrafe del libro resumía bien la incompatibilidad entre ser católico y masón, así como el «rol disolvente» que tenía la masonería sobre la sociedad: «No se puede ser a la vez francmasón y cristiano, porque la Francmasonería es enemiga irreconsiliable [sic] del Cristianismo, y por consiguiente es enemiga funesta de la sociedad» (Passarell 1886). En esta línea, en la católica Arequipa empezaron a circular folletos contra la masonería, uno de los tantos «enemigos del país». En el panfleto ¡Al pueblo católico! (1888: 31), traducido del francés, se denunciaba la destrucción de todo principio religioso y de autoridad provocada por la masonería. Las consecuencias se podían ver en la Francia revolucionaria y en el asesinato del católico presidente ecuatoriano García Moreno. La aparición de la masonería como enemiga del catolicismo arequipeño, y peruano, era un eco de la condena papal a las sociedades

7 Encíclica de Nuestro Santísimo Padre el Papa León XIII, sobre la francmasonería dirigida a los venerables Patriarcas, Primados, Arzobispos y Obispos de todo el universo católico, en gracia y comunión con la Santa Sede Apostólica (1884). Arequipa: Imprenta de La Bolsa. 
masónicas de 1884, y constituye un ejemplo de la recepción del magisterio pontificio en la Iglesia arequipeña. La retórica papal no era simplemente copiada, pues era adaptada a la realidad local en el plano discursivo, como da cuenta la pluma de Huerta. Pero, también, la palabra inspiraba la acción.

La actitud de Huerta respondía a todo un contexto político y religioso exaltado desde 1886 por la ley de secularización de los cementerios, la propuesta de la tolerancia de cultos y la expulsión de los jesuitas del país. Los enemigos de la Iglesia parecían avanzar con rapidez en el país. Muchas asociaciones laicales, como la Unión Católica fundada en Arequipa en 1886, se habían manifestado contra el avance de masones, liberales y protestantes. Estos laicos recibieron el soporte de Huerta, quien reconocía en la nueva sociedad una respuesta laical a las llamadas papales de Pío IX y León XIII para enfrentar el avance del liberalismo y la masonería. En la instrucción pastoral dirigida a los miembros de la Unión Católica, el prelado recomendaba leer el capítulo 24 del Evangelio de San $\mathrm{Mateo}^{8}$ para tomar consciencia de la persecución que vivían los católicos y la necesidad de defender con perseverancia la fe (Huerta 1886a: 3-4). El surgimiento de la militancia laical, promovida por Huerta, ayudó a fortalecer el resurgimiento católico en Arequipa a través de la presencia de este nuevo actor en el espacio público local y, más adelante, político. El obispo colaboró con el laicado y coordinó temas sensibles como la organización de una protesta contra la expulsión de los jesuitas. Por ejemplo, en enero de 1887, se reunieron en el Palacio Episcopal el obispo, el consejo directivo de la Unión Católica, miembros de la curia y tres sacerdotes jesuitas para preparar una manifestación escrita contra la expulsión de los jesuitas. Sin embargo, la reunión fue abruptamente interrumpida hacia las nueve de la noche, cuando las autoridades ingresaron en la

8 En Mt 24, Jesús describe en tono escatológico los padecimientos que sus discípulos sufrirán en el tiempo previo a su segunda venida para juzgar a la humanidad. 
residencia episcopal — tras derribar la puerta - para llevarse a los jesuitas al exilio. Los laicos denunciaron que la gendarmería recorrió el palacio episcopal, incluida la capilla y el cuarto del prelado, de manera que «los ministros de las tinieblas [la gendarmería] parodiaron tristemente la escena del Huerto de los Olivos» (UCA 1887: 7-8). De esta manera, no solo el prelado era portador del lenguaje ultramontano, sino que los laicos y laicas se insertaron rápidamente en el espíritu y la retórica de este «nuevo catolicismo» que les abría espacio como activos agentes de su fe.

Huerta también otorgó soporte episcopal a otras asociaciones laicales. Promovió las asociaciones piadosas, juntó a las devociones por los Sagrados Corazones de Jesús y María y por el Romano Pontífice. En 1887, el obispado organizó una serie de actividades durante todo el año por el jubileo sacerdotal de León XIII. Participaron el prelado, el Cabildo eclesiástico, el Consejo Provincial, el rector y profesores de la Universidad de San Agustín y las dos asociaciones laicales más importantes de la ciudad, la Hermandad de San José y las ramas masculina y femenina de la Unión Católica. Huerta demandó, en una breve pastoral, recordar que «la causa santa que él [León XIII] defiende es nuestra causa» (Huerta 1887: 2), por lo que había que orar por él y saber que:

[...] no estamos solos en el mundo, carísimos: somos más de doscientos millones los que sentimos latir en nuestro pechos un corazón católico: más de doscientos millones los que nos asociamos a nuestro venerado Pontífice, de lo íntimo de nuestra alma; que sentimos como él siente, que pensamos como él piensa, que queremos lo que él quiere [...] Más de doscientos millones que estaremos unificados en espíritu con nuestro Padre y Pastor Supremo el ansiado 31 de Diciembre del presente año [fecha de inicio del jubileo por los cincuenta años de sacerdocio del papado]. ${ }^{9}$

$9 \quad$ Huerta (1887: 4). 
La exhortación de Huerta, por la efeméride, destacaba la dimensión global de la presencia del pontífice en el mundo católico. Sin conocerse ni verse, los católicos eran parte de una comunidad religiosa universal, en que todos tenían espacio, y que se encontraba unida en sus sentimientos comunes alrededor del papa, así como en las luchas del catolicismo global. En Arequipa, los fieles arequipeños se reunieron el 30 de septiembre para conmemorar el jubileo papal, en común oración por las almas del purgatorio, como había solicitado León XIII a toda la Iglesia universal (Martínez 1933: 276). Este signo público de fe manifestaba la fuerza de la retórica ultramontana, defendida y deseada por el prelado. Para Huerta y los católicos militantes, la fe católica en Arequipa tenía una dimensión pública.

Sin embargo, la unanimidad católica comenzó a ser cuestionada por la pequeña, pero creciente, presencia protestante en el país. Como destaca Armas, antes de 1890 las denuncias contra el protestantismo fueron escasas y ocasionadas o por ellos mismos u otros funcionarios públicos (1998: 151). Pronto Arequipa y su ultramontano prelado colisionaron con la primera presencia protestante. El 1 de enero de 1889, el metodista Francisco Penzotti, mientras vendía biblias en la ciudad de Arequipa, se cruzó «cara a cara» con el obispo Huerta, que ordenó a un gendarme su inmediato apresamiento mientras él enviaría una denuncia a la intendencia. Cuando Penzotti fue apresado preguntó «نंorden de quién?», «Del obispo» respondió el policía. Pronto se unirían a Penzotti en prisión, Arancet y el recién convertido José Illescas, quienes unos días habían sido apedreados en Cocachacra (cerca de Mollendo) por intentar vender biblias y predicar (Armas 1998: 153, nota 45). El poder y el prestigio del obispo Huerta en Arequipa eran tremendos, como daba cuenta la orden dada al policía. Sin embargo, el cónsul italiano en Arequipa, ante la arbitrariedad de la detención, comunicó a Lima la situación. En la capital, los políticos liberales que buscaban atraer la migración europea presionaron al presidente Cáceres, quien en telegrama or- 
denó la liberación de los detenidos, tras diecinueve días en prisión (Armas 1998: 154-155). La situación daba cuenta que los intereses doctrinales, morales y jurídicos de la Iglesia colisionaban con los del Estado, afincado en la «ambigua» Lima. La católica Arequipa era derrotada, pero no sometida.

Desde 1891 el obispo mostró signos de debilidad física, por lo que tuvo que mudarse a Lima. El año anterior promovió la fundación del periódico católico El Deber y se hizo eco de la primera encíclica social de León XIII, la Rerum Novarum, sobre la situación de los obreros. En la carta de presentación del documento papal, Huerta mantuvo su postura ofensiva y consideraba que el retorno a la «bondad misericordiosa» de Jesús podía evitar caer en «doctrinas más disociadoras y disolventes que la impiedad ilustrada de nuestros días» (1891: 2). Con ello, el prelado reconocía los nuevos peligros ideológicos y políticos para el catolicismo del nuevo siglo: «el socialismo, el comunismo, la internacional y aún el nihilismo ruso» (1891: 2). La recepción de la encíclica leonina la realizó en clave apologética, pues lo central era oponerse a los enemigos del catolicismo. Huerta había sentado las bases de la retórica ultramontana en Arequipa y promovió la militancia católica de laicas y laicos. Podía sentirse como un gran defensor de la «causa católica» en Arequipa, en el Perú, y en la Iglesia. No obstante, el prelado no vería el giro hacia la cuestión social, la gesta del catolicismo social en Arequipa y la progresiva apertura política del laicado. El 3 de diciembre de 1896, a solicitud de Huerta, se nombró obispo in partibus y coadjutor ${ }^{10}$ al arequipeño Manuel Segundo Ballón. El 9 de junio de 1897, la vida del combativo obispo se apagó en Lima.

10 El obispo coadjutor es nombrado para ayudar en el gobierno y cuidado pastoral de una diócesis, como lo hace un obispo auxiliar, con la diferencia de que tiene derecho a sucesión a la muerte del obispo titular. 


\section{El fracaso de la intransigencia: el obispo Manuel Segundo Ballón MaNrique aNTE La MODERNIDAd AREQUiPEÑa}

Manuel Ballón nació en Tiabaya, ubicado a unos diez kilómetros de la ciudad de Arequipa, el 31 de mayo de 1854. En 1878 ingresó al Seminario de San Jerónimo y recibió el orden sacerdotal en Cusco el 15 de agosto de 1879, de manos del obispo Julián Ochoa. Dada sus cualidades intelectuales, se le nombró profesor de «Religión»e «Historia eclesiástica» en el seminario arequipeño (Martínez 1933: 281). El curso de «Historia eclesiástica» se había convertido en una importante herramienta ideológica del ultramontanismo, pues les permitía demostrar la autoridad absoluta del pontífice y la romanización de la Iglesia desde su fundación realizada por Jesús hasta el momento presente. ${ }^{11}$ Ballón fue también profesor del Colegio Nacional Independencia y del Colegio Santo Tomás de Aquino, lo que le permitió estar involucrado activamente con el mundo pedagógico y académico de la ciudad. Igualmente daba clases de religión en las escuelas nocturnas de obreros, del Círculo de Obreros Católicos, y que eran parte del inicio del catolicismo social en Arequipa. Como parte de su labor docente publicó diversos libros sobre filosofía elemental y moral, fundamentos y dogmas del catolicismo, psicología y lógica, moral para niños y algunos tratados de derecho canónico (Garreaud 2015, 3:32-33). En sus tratados — muchos de ellos dirigidos a la educación de los niños-desarrolló varias ideas centrales del catolicismo del cambio de siglo, como la importancia de la familia para la conservación de la sociedad y la fe (Ballón 1883: 50-51).

11 Para un estudio sobre la influencia de la teología ultramontana, en temas como la inmutabilidad de sus estructuras, en la escritura de la historia de la Iglesia en el Perú, consultar Iberico (2015). Sobre este tema, afirmaba Ballón: «Leed la historia, y encontraréis que todos los Sumos Pontífices han guardado y defendido en todo tiempo con asombrosa fidelidad, con una constancia verdaderamente divina, el precioso tesoro de la verdad y de la fe que el mismo Dios le ha confiado» (citado en Garreaud 2015, 3: 34). 
Por su activo compromiso con la educación religiosa, el gobernador eclesiástico lo nombró censor de las obras publicadas e importadas a Arequipa, así como juez adjunto del tribunal eclesiástico y encargado de iniciar el proceso de beatificación de Ana de los Ángeles Monteagudo (Martínez 1933: 282-283). ${ }^{12}$ Para Ballón, la labor educativa era central en la Iglesia como garantía de la ortodoxia y la conservación de las generaciones futuras dentro del catolicismo. Además de los cargos eclesiales, ocupó puestos importantes en la municipalidad de la ciudad como el de Inspector de Instrucción, de Estadística y Registro del Estado Civil; miembro de las comisiones de higiene y preparación de los informes anuales; y síndico de rentas (Martínez 1933: 284). Martínez afirma que rehusó asumir la alcaldía de la ciudad (1933: 284). Posiblemente los compromisos eclesiales provocaron que Ballón rechazara el puesto. En 1890, tras ser presentado por el obispo Huerta, recibió una canonjía doctoral en el Cabildo eclesiástico de Arequipa, y seis años después fue instituido como obispo in partibus y coadjutor, lo que le permitió asumir en agosto de 1898 el obispado de Arequipa.

Formado en el espíritu ultramontano, no logró comprender con profundidad los cambios culturales que vivía la ciudad desde inicios de 1890. Estos cambios, impulsados por el comercio y ciertos nuevos hábitos instalados en la ciudad, lo convirtieron en un activo combatiente del proceso de modernización de la ciudad y de la progresiva secularización. En su primera carta pastoral, el nuevo obispo afirmaba que: «Desgraciadamente hay que combatir con enemigos formidables que nos asaltan a cada paso. [...] Excluyen absolutamente el nombre santo de Dios, de los juramentos y de las leyes, de los parlamentos y asambleas, de los colegios y escuelas, y llegan hasta el extremo de querer que los matrimonios, los bautizos y los funerales sean civiles o sin Dios» (Ballón 1898: 13). Ballón con-

12 Sor Ana de los Ángeles Monteagudo fue beatificada el 2 de febrero de 1985 por el papa Juan Pablo II en Arequipa, durante su primera visita al Perú. 
sideraba necesario establecer una actitud combativa contra los «enemigos de la Iglesia y de Dios», representados por los grupos liberales y masones surgidos en el ambiente de progresiva secularización de las ideas y estilos de vida, ${ }^{13}$ fortalecidos por la modernización comercial de Arequipa y el cambio de hábitos de vida de las clases involucradas directa o indirectamente con el sistema emergente (Flores Galindo 1993: 341). Como su predecesor, temía que la «católica Arequipa» cayese víctima de sus enemigos, muchas veces vinculados al Estado. La secularización de ciertas prácticas e instituciones — hasta entonces monopolio de la Iglesia católica - como los registros y los cementerios impactaron fuertemente en la mentalidad ultramontana del obispo y de la Iglesia en general. La sacralidad de estas prácticas e instituciones, consideradas como parte de la estructura sagrada de la misma Iglesia — por poner un ejemplo, un cementerio era un lugar santo en el que los cristianos inhumados esperaban el juicio finaleran destruidas en el marco de las transformaciones seculares del Estado. Estos cambios cuestionaban la función de lo sagrado como estructurador del orden terrenal.

En 1899 participó como delegado del episcopado nacional junto a los prelados Manuel Tovar, de Lima, Ismael Puirredón, de Puno, y Juan Antonio Falcón, del Cusco, en el Concilio Plenario de la América Latina en Roma, que había sido convocado por el papa León XIII. En la pastoral de despedida, Ballón solicitaba a sus fieles orar por él y los obispos reunidos en Roma, y ordenaba la celebración de una misa del Espíritu Santo en la catedral y las parroquias el 28 de mayo de 1899, día del inicio del encuentro. Además, se debía celebrar las letanías de todos los santos y la oración Deus, cui omne cor patet al final de cada misa durante el tiempo del concilio (Ballón

13 Taylor establece que la secularización se puede comprender, en el tercer sentido, como un proceso de debilitamiento de la opción exclusiva de la fe para comprender el mundo y la experiencia de vida frente a otros modelos de comprensión del mundo y de la vida. La fe se vuelve una opción entre otras (Taylor 2014, I: 22-23). 
1899a: 5). ${ }^{14}$ A través de la liturgia, el obispo involucró en la celebración conciliar a la feligresía arequipeña. El viaje a Roma vigorizó la experiencia ultramontana de Manuel Ballón, como lo manifestó a su regreso en la carta pastoral dirigida a su clero y feligresía. Destacaba haber encontrado en Roma un suelo santificado por la sangre de «millares de mártires», haber tenido la «dicha» de ver la columna «en que fue azotado el Salvador del Mundo» y haber besado y subido de rodillas la Escala que Jesucristo «santificó con su Sangre y con sus plantas divinas». También se encontró en la Cátedra pontificia el lugar donde san Pedro «dio su vida en testimonio de su fe» y contempló las fuentes surgidas en el lugar donde fue decapitado san Pablo. En Roma, señalaba, «carísimos hijos, hemos experimentado de un modo muy especial la protección divina». Las cosas «sublimes» y la reunión de los obispos en el concilio dan la «íntima convicción» de la presencia de Dios (Ballón 1899b: 5). Además, se publicaron en Arequipa los indultos pontificios sobre el ayuno, la abstinencia y la limosna —solicitado por los obispos y que duraron hasta 1909considerando la situación de los fieles latinoamericanos (Ballón 1899c), y una carta sinodal de los obispos reunidos en Roma donde señalaban la importancia del concilio, a causa de los cuatrocientos años del descubrimiento de América (Carta Sinodal 1899). El prelado experimentó la romanité, que afianzó sus posturas ultramontanas y la vehemencia contra los enemigos de la Iglesia.

La inexorable proximidad del nuevo siglo era ocasión para conmemorar el decimonoveno natalicio de Jesucristo. Por ello, el obispo organizó una visita pastoral a toda la diócesis que le permitió

14 La oración Deus, cui omne cor patet se rezaba para solicitar el cumplimiento de la voluntad de Dios. La plegaria es como sigue: «Oh Dios, a quien todos los corazones están manifiestos, todos los deseos son conocidos, y de quién es ningún secreto oculto, purifica por la infusión del Espíritu Santo, los pensamientos de nuestros corazones, que perfectamente te amemos y dignamente magnificar. Por nuestro Señor Jesucristo, quien vive y reina, en unidad del Espíritu Santo, por los siglos de los siglos. Amén» (traducción del latín realizada por el autor). 
establecer nuevas normas sobre diversos temas como la celebración de los sacramentos, el santísimo sacramento y su exposición, así como otras relacionadas al templo, la sacristía, el cementerio, los funerales, los bienes eclesiásticos, el archivo parroquial, las procesiones, las costumbres del pueblo y la vida religiosa de las cofradías (Ballón 1900a: 9-38). La visita del obispo a cada parroquia e iglesia de la diócesis culminaba con la convocatoria a un pequeño jubileo concedido por León XIII, después del concilio romano de 1899. La visita se interrumpió para dar paso a las celebraciones de fin de siglo y se continuó durante el año 1901. En todo momento, León XIII — un papa físicamente lejano, pero espiritualmente cercano a su feligresía - se hizo presente a través del jubileo concedido con ocasión de la visita a la diócesis realizada por Ballón (1900a: 6). Con ello, la experiencia vivida por Ballón junto al papa se trasmitió a las parroquias e iglesias de la diócesis a través de los jubileos pontificios, que mostraban la presencia del papa en medio de los fieles. En 1901, por pontificia orden de León XIII, se extendió el jubileo con indulgencia plenaria a todo el mundo católico. Ballón ordenó la celebración en la diócesis, junto a la conmemoración de la fiesta del Sagrado Corazón de Jesús que el papa estableció celebrarse en junio en toda la Iglesia universal (Ballón 1901).

A monseñor Ballón le tocó acompañar el cambio de siglo, considerado por los ultramontanos como la centuria más contraria a la Iglesia católica y que, como reconocía el mismo obispo: «El siglo XIX, carísimos hijos, tendrá, pues, que derramar lágrimas, para reparar tantos males que ha hecho» (Ballón 1900c: 9). Para reparar el daño e iniciar el nuevo siglo con un renovado impulso cristiano, algunas diócesis celebraron el cambio de época con gestos simbólicos como el que ocurrió en las iglesias de Lima, donde se instalaron cruces de mármol con la inscripción Christus regnat, vincit et imperat, que hacía referencia al reinado (regnat), a la victoria (vincit) y el dominio (imperat) de Cristo sobre el mundo, el país y el nuevo tiempo. En Arequipa, el obispo organizó un ascenso al Misti para celebrar una 
eucaristía el 21 de octubre de 1900 y levantar una cruz metálica de diez metros de largo y cuatro metros y medio de ancho. El obispo dispuso una serie de celebraciones penitenciales para «pedir perdón por los pecados del mundo» entre el 17 y el 20 de octubre, cuando se inició su ascenso al emblemático volcán arequipeño. La celebración de la ciudad se extendía a los otros pueblos de la diócesis, donde se instalarían otras cruces para recordar el «XIX centenario del nacimiento del Salvador». ${ }^{15} \mathrm{El}$ «XIX» no solo era ocasión para lamentar las grandes pérdidas del catolicismo, sino también para conmemorar el nacimiento de Jesucristo.

La ceremonia se celebró en dos espacios paralelos. Los fieles reunidos en la Pampa de Miraflores acompañaron la peregrinación de ascenso del prelado con una misa celebrada por el canónigo Manuel Lorenzo Bedoya. La Pampa se llenó de diversas imágenes devocionales de la ciudad, algunas de ellas vestidas con trajes penitenciales como había solicitado el obispo en su carta pastoral (Ballón 1900c: 18). A la misa acudieron varios miles de fieles (Benito 1998: 46). Por concesión pontificia al mundo católico, Ballón extendió la bendición de Jesucristo a la ciudad de Arequipa y mandó prepararse para la misa de final del siglo el 31 de diciembre de 1900, para que «den públicamente gracias a Dios por todos los beneficios recibidos de su mano bondadosa durante el siglo que termina y obtener los necesarios para que el nuevo siglo sea feliz» (Ballón 1900c: 21). La manifestación pública de fe mostraba la fuerza de convocatoria y la apropiación de la efeméride de cambio de siglo por parte de la

15 Estas cruces debían tener grabado la siguiente inscripción: «1900 - Viva nuestro Señor Jesucristo - 1901 // A Jesucristo Dios y Hombre verdadero / / Salvador y Rey de la humanidad / / Tributan este homenaje de su fe y amor // Los fieles de la parroquia [...] // Siendo Sumo Pontífice León XIII // Obispo de esta Diócesis de Arequipa // El Iltmo. Dr. D. Manuel Segundo Ballón / / Y cura de esta parroquia // El Sr. D. [...]». Adicionalmente, Ballón recomendaba tener una práctica piadosa, pues el papa León XIII concedía cien días de jubileo a los fieles que besaren la cruz y rezaren un Padre nuestro (1900c: 20-21). 
Iglesia católica, en un contexto marcado por el ascenso de la crítica contra la religión y sus valores en Arequipa, de nuevas ideologías y de una creciente presencia protestante. El cierre del siglo se dio en un contexto eclesial internacional marcado por el giro de León XIII hacia una nueva relación de la Iglesia católica con el mundo moderno, especialmente con la promoción de la acción social católica entre los laicos y laicas (Cárdenas 2018: 159-161). En este sentido, Ballón otorgó su respaldo a las organizaciones laicales como la Unión Católica, a través de la reforma de esta sociedad para reforzar su carácter apologético y profundizar la defensa contra «los ataques que los enemigos de la religión hacen a las creencias católicas y a la piedad de este pueblo» (El Deber 8.VIII.1900: 2). Por ello, el directorio debía «ganar terreno como el centinela avanzando y [que] cuida y vela por el catolicismo de Arequipa» (El Deber 8.VIII.1900: 2).

No obstante, el cambio de siglo no calmó las movidas olas en Arequipa. La labor apologética del prelado se reforzó con la condena de los escritos «impíos e inmorales» que circulaban en su diócesis, junto a las actividades nuevas como «novelas y pinturas obscenas, y representan comedias antirreligiosas, y saturadas de tanta inmoralidad» (Ballón 1900b: 4). La actitud ofensiva se repitió en 1904 cuando se planteó el matrimonio civil en el parlamento, pues Ballón afirmaba que «el llamado matrimonio civil solo puede concebirse, pues en los pueblos que han perdido toda idea de Dios y de religión, o que admiten el herético y lamentable absurdo de que el Estado es Dion》 (Ballón 1904: 14). En abril de 1901, Ballón publicó la encíclica leonina sobre la democracia cristiana, Graves de Communi Re (18 de enero de 1901), con una breve introducción donde destacaba los «errores socialistas que, desgraciadamente, cubren el mundo amenazando su ruina, y permite a los hombres ver los escollos y peligros que le amenazan en la vida social» (Ballón 1901: 3-4). ${ }^{16}$ Sin

16 Esta lectura apologética de la encíclica de León XIII ocurrió en otras diócesis iberoamericanas, a causa de la perspectiva ultramontana de la sola defensa de 
embargo, la lectura del prelado no reflejaba la complejidad y ambigüedad política trazada por el pontífice sobre la participación política de los laicos en la arena pública democrática, ni la valoración de las nuevas formas políticas como el régimen democrático (Chadwick 1998: 320-322). Entre la defensa de la cuestión social, el papel de la religión en la vida pública y la defensa de la fe católica, León XIII perfiló una vía para la participación pública de los católicos en el plano social y político, no sin ambigüedades e idas y venidas, y sin renunciar a la intención apologética.

Desde inicios del siglo XX se instalaron en Arequipa grupos liberales y protestantes. Desde 1904 operaban en la ciudad miembros de la Sociedad Británica, asociados a Eduardo Forga, destacado miembro de la élite industrial arequipeña. Además, desde 1906, se les unió la Unión Misionera para Regiones Lejanas (RBMU), que junto a Forga extendieron sus redes hasta Cusco, donde forjaron el proyecto de la hacienda Urcos (Armas 1998: 148-149). Además, el ambiente político arequipeño se vio sacudido con la fundación del Partido Liberal, al comenzar el siglo, que daba institucionalidad al liberalismo regional y a los críticos de las élites y el catolicismo. Los liberales fueron críticos del empobrecimiento de amplios sectores de la ciudad, producido por el crecimiento comercial y la progresiva consolidación de la élite y la burguesía (Carpio 1990: 550). En las páginas de El Ariete, el órgano publicitario, denunciaban la nueva esclavitud del obrero por obra de su amo el burgués o capitalista. Por ello, criticaban a «las clases acomodadas» que «hacen alarde también de ser poseedores de una supremacía moral que ni siquiera comprenden» (Lino Urquieta, «Discurso» en El Ariete, año 1, núm. 3, citado en Carpio 1990: 550). La contradicción entre

la fe católica. Un claro ejemplo fue el obispo de Zamora (España), Luis Felipe Ortiz, quien dedicó en su casi totalidad la presentación de la encíclica papal a condenar el socialismo y sus consecuencias nocivas en la sociedad (Hernández 2016: 224). 
la fe y la vida era criticada por los liberales arequipeños. Inclusive, Modesto Málaga afirmaba que ellos eran:

[...] enemigos del clericalismo apóstata de ese clericalismo que en vez de ceñir sus actos a las doctrinas de la religión, los ciñe a sus bajas pasiones y a sus encendidos odios; de ese clericalismo que en lugar de ser redentor es verdugo, que en lugar de ser reflejo de caridad y de mansedumbre, es retrato de avaricia, de soberbia, de lujuria, de odio; somos enemigos de ese clericalismo inquisidor que cree ver en cada libertad a una enemiga del cielo; que cree ver en el progreso un reflejo del infierno; que cree ver en cada conciencia libre una rebelión, y en cada derecho individual una anarquía. ${ }^{17}$

No se trataba de una crítica anticlerical feroz y laicista, sino de un anticlericalismo crítico de la actitud complaciente de la Iglesia católica con el sistema económico y social de Arequipa. Con el silencio cómplice ante la pobreza, y la inquisitorial locuacidad contra la «libertad» y la defensa de sus prerrogativas.

Muy cercano a los liberales se encontraba Eduardo Forga, quien fundó en 1904, junto a David Watkins, la Iglesia Evangélica Independiente de Arequipa. En ella colaboraron Felipe Muñoz y Ramón Espinoza, quienes establecieron una oficina de venta de biblias en la ciudad y sus alrededores. Estos últimos fueron atacados por una turba de católicos (Fonseca 2002: 97-102). La reacción católica, muy cercana a la radical intolerancia de Huerta, daba cuenta de que Ballón era un prelado ultramontano más de la primera generación. Forga facilitó la colaboración entre liberales y protestantes, por la coincidencia de intereses en contra del catolicismo, especialmente por la búsqueda conjunta de la tolerancia de cultos (Armas 1998: 174-175). La crítica liberal contra el catolicismo logró presencia pública el 9 de abril de 1905, cuando se realizó el primer mitin

17 Modesto Málaga, «El Ukase eclesiástico» en El Ariete, 17.IV.1902, citado en Carpio (1990: 549). 
anticlerical en la Plaza de Armas de la ciudad, frente a la catedral. Se reunieron para solicitar a las autoridades civiles el cumplimiento de la resolución del gobierno central de convertir el Palacio Episcopal del Buen Retiro en un lazareto provisional, ante la crisis de salud desatada por la peste bubónica en Mollendo y Arequipa. El prelado se opuso a esta medida (Ballón 2001: 159).

La presión de los liberales se vio favorecida por la actitud liberal del prefecto Alvizuri, denunciado por el diario católico El Deber como alguien guiado y agradecido con los liberales (13.IV.1905: 2). ${ }^{18}$ Los editores denunciaron que el verdadero objetivo del mitin había sido «insultar públicamente al Iltmo. Obispo y hacer escarnio de la Religión que el Estado garantiza» (11.IV.1905: 2). La retórica católica de la defensa de la exclusividad del culto católico — sostenida en el artículo 4 de la Constitución — iba perdiendo peso en el debate nacional desde fines del siglo XIX, a causa de la política favorable a la inmigración extranjera. Los liberales consiguieron que se tomara el palacio del Buen Retiro con el uso de la fuerza pública. El obispo Ballón quedó desprestigiado, desautorizado, deslegitimado y cargó con el peso de su falta de caridad por negarse a convertir su palacio en un lazareto, en plena crisis de salud en la región de Arequipa. En consecuencia, se vio obligado a renunciar al obispado en carta al papa Pío X (Ballón 2001: 164). ${ }^{19}$ El ultramontano combate del pre-

18 En unos cablegramas enviados a Carlos Elías, presidente de la Unión Católica de Lima, se informó que uno de los organizadores del mitin, Chávez Bedoya, apareció por la ventana de la prefectura con el prefecto Alvizuri. Los otros organizadores fueron Frisancho y Mostajo. Además, un obrero de apellido Goizueta se dirigió a Alvizuri para solicitarle tomar el Buen Retiro y la supresión del artículo 4 de la Constitución, sobre la exclusividad del culto católico (El Deber 11.IV.1905: 2).

19 En carta del 9 de abril, el obispo informó al prefecto de la imposibilidad de entregar el Buen Retiro por cuestiones de salubridad, pues «se pone en inminente peligro de contagio al Monasterio de Santa Rosa, al Colegio Salesiano, a la importante población de San Antonio, a la Ranchería y en consecuencia a toda la ciudad» (El Deber 12-IV-1905: 2). El 10 de abril, los miembros de la 
lado contra «las fuerzas del mal», inscrito como un programa en su escudo episcopal, Virgo, cunctas haereses sola interemisti ( $(\mathrm{OH}$, Virgen, tú sola has destruido todas las herejías»), culminó en 1905 con su renuncia al episcopado arequipeño. Ballón no logró insertarse en la política menos vehemente de León XIII, pues estaba más forjado en el ultramontanismo de Gregorio XVI y, especialmente, de Pío IX, caracterizado por la impetuosidad y la intransigencia. El arzobispo de Lima le concedió el Deanato del Cabildo Metropolitano. El prelado falleció en Lima el 27 de agosto de 1923. Las fuerzas católicas en Arequipa quedaron advertidas del poder liberal y de la muy cercana, pero sutil, presencia protestante.

\section{Hacia el Catolicismo Social: el obispo Mariano Holguín y la BÚSQUEDA DE COMPRENDER LA MODERNIDAD}

Mariano Holguín Maldonado nació en Arequipa el 5 de octubre de 1860. A los veinte años, el 25 de mayo de 1881, ingresó como religioso a la Recolección Franciscana de San Jenaro, conocido como el Convento de la Recoleta, donde profesó con el nombre de Mariano de la Concepción, por su devoción a la Virgen María. En 1886 fue ordenado sacerdote y tuvo por madrina a Maximiana López de Romaña, activa colaboradora de la Iglesia en Arequipa, conocida como la «santa de San Camilo», por la calle en la que se ubicaba su casa (Cabré 1959: 48). En 1891, Holguín fue elegido Guardián por tres años de su convento, cargo al que fue electo por segunda vez en 1897. Su carrera eclesiástica no se detuvo, pues en 1899 fue elegido por el Padre General de su orden como Comisario General de la Provincia Franciscana de los XII Apóstoles. Al dejar

Unión Católica y otros señores de la ciudad firmaron un acta de desagravio por los insultos contra el obispo (El Deber 14.IV.1905: 2). No obstante, la suerte del obispo estaba echada por la dura oposición liderada por los liberales. 
el cargo de Guardián, en 1899, la Recoleta de Arequipa era uno de los conventos con mayor actividad asociativa y pública de la ciudad con cincuenta y cinco miembros: dieciocho sacerdotes, doce coristas, nueve legos, seis donados, siete novicios y tres postulantes (Cabré 1959: 55-56).

Como muchos clérigos citadinos de entonces, fue formado en el ultramontanismo apologético. En 1899, fray Mariano defendió el derecho a la propiedad de la Iglesia al señalar que:

La Iglesia ha recibido de su Divino Fundador el derecho de existir y conservarse en todo el orbe, independientemente de toda potestad humana. El Hombre Dios al establecer la Iglesia, no le impuso el deber de obtener licencia de Tiberio ni de ningún monarca de la tierra para subsistir y propagarse. [...] Si pues la Iglesia existe y se propaga tan sólo en virtud del derecho, o, mejor dicho, el deber que le impuso su Divino Fundador, independientemente de toda potestad temporal; como el derecho de poseer nace del derecho de existir y conservarse, se sigue que la Iglesia tiene el derecho de propiedad absolutamente independiente de toda potestad. ${ }^{20}$

No obstante, su ultramontanismo apologético se empapó del catolicismo social surgido desde 1880 en Europa y legitimado eclesialmente en la encíclica Rerum Novarum (1891) de León XIII. En respuesta a la cuestión social y en consonancia con la invitación del pontífice, el 19 de marzo de 1896 fundó el Círculo de Obreros Católicos de Arequipa.

En 1903 se trasladó a Roma para participar como elector del Ministro General de la Orden y fue elegido Definidor General, es decir, miembro del consejo de gobierno universal de la orden franciscana (Martínez 1933: 292; Cabré 1959: 82). En Roma, Holguín pareció estar consagrado a las labores de la curia de su orden de forma permanente. Sin embargo, el congreso nacional lo nombró en

20 Citado en Garreaud (2015, 3: 42). 
diciembre de 1903 prelado de la diócesis de Huaraz. Se reunió con el papa Pío X para confirmar la elección del congreso, y del papa recibió su fotografía autografiada — que se conserva en el Convento de La Recoleta-, un pectoral episcopal y varias bendiciones apostólicas. En octubre, tras su llegada a Lima, fue consagrado obispo en la catedral capitalina (Cabré 1959: 88-90). Su breve episcopado huaracino lo hizo famoso entre sus feligreses, cuyos representantes en el parlamento, en octubre de 1905, se opusieron a su traslación a la sede de Arequipa. Sin embargo, Pío X confirmó su cambio al obispado de Arequipa en junio de 1906, ciudad donde fue recibido con una ceremonia en la universidad y un banquete organizados por el Centro Social Católico (Martínez 1933: 310-311).

La experiencia franciscana y su estancia en Roma permitieron al obispo Holguín conjugar su ultramontanismo apologético con una fuerte comprensión de los problemas sociales y culturales, producidos por los cambios «modernizadores» que ocurrían en Arequipa. Estaba dispuesto a combatir las herejías modernas, como sus dos antecesores, pero como afirmaba su escudo, Non veni ministrari sed ministrare («No he venido a ser servido sino a servir»), ${ }^{21}$ las «herejías» también abrieron espacio para la preocupación social. Esta labor fue el signo de su trabajo episcopal y público en sus treinta y nueve años de gobierno. Su actividad representaba un ultramontanismo más social, iniciado en Europa en respuesta al desafío social y político producido por la industrialización, y convertido en prioridad por el papa León XIII con la encíclica Rerum Novarum. La llegada de Holguín a la sede arequipeña se produjo en un momento de consolidación de los cambios en la ciudad, que en 1908 contaba con treinta y cinco mil habitantes, con pequeñas industrias y Mollendo consolidado como puerto de exportación (Klarén 1992: 257 262). Además, los grupos liberales y protestantes se fortalecieron y lograron mayor publicidad luego de la renuncia de su antecesor. Por

21 Cita del Evangelio según san Mateo, capítulo 25, versículo 28. 
lo que las relaciones entre liberales y protestantes se estrecharon. Prueba de ello fue que, en 1907, el misionero protestante Jarret expresó públicamente, en las páginas del periódico La Bandera Roja, cuál era la auténtica relación entre el cristianismo y el liberalismo: «Si la clase obrera abraza el cristianismo, abandonando el catolicismo, oirán la palabra de Cristo que les dice: "La verdad os hará libres”» (citado en Fonseca 2002: 113).

A su llegada a Arequipa, el nuevo prelado encontró un escenario político y religioso complejo y en un creciente proceso de pluralización social y política. Ante la muestra de la alianza protestanteliberal, el obispo Holguín se vio obligado a cambiar la relación de la Iglesia con el proceso modernizador, con miras a reformular la oposición al liberalismo que pasaba por abordar la situación social arequipeña. En esta línea, en 1907, el prelado inició un nuevo proceso de reforma de la Unión Católica de Arequipa, la más importante organización laica, que afianzó la presencia del clero en el organigrama del directorio de la asociación, al nombrar a un sacerdote como representante suyo. Además, ordenó la apertura de los registros de inscripción para todo varón arequipeño dispuesto a vincularse en la defensa de su fe (El Deber 2.III.1907: 3). Igualmente, el obispo fortaleció las sociedades de caridad, promovió el Círculo de Obreros Católicos y buscó articular las sociedades laicales presentes en la ciudad. Por ello, decidió fortalecer el papel de los laicos e incentivar una participación pública, no solo en el ámbito de la defensa de la fe, sino social para enfrentar las críticas de los liberales y evitar el avance de sus ideas entre los sectores trabajadores.

Ese mismo año, el obispo Holguín organizó las Escuelas Dominicales orientadas a los niños pobres de la ciudad. En la escuela se les enseñaba a leer, escribir y «las principales verdades del Catecismo», que se convirtieron desde 1919 en el Catecismo dominical, liderados por los padres franciscanos de La Recoleta y sostenidos por «señoritas piadosas que los domingos sacrificaban su legítimo descanso para ir a enseñar la doctrina cristiana a los niños del pue- 
blo» (Garreaud 2015, 3: 46). Muchas de estas jóvenes provenían de asociaciones como la Unión Católica de mujeres y eran parte de las clases media y alta de la ciudad. De esta manera, el prelado promovió y colaboró con el trabajo de los laicos y laicas arequipeños como forma de entrar en el espacio público. Sin perder de vista el liderazgo de los clérigos, Holguín reformó la Unión Católica de varones para fortalecer el catolicismo entre sus miembros que es «como una institución social redentora» y evitar que como todas «las sociedades modernas se paganizan y hay que volverlas a Cristo» (El Deber 2.III.1907: 2). Su presencia, también, fue activa entre las señoras de la Unión Católica con quienes participaba de las celebraciones litúrgicas, en la formación de las escuelas dominicales y en la obra social de los bazares para repartir bienes entre los pobres. El soporte del laicado fue central en el programa del monseñor Holguín para responder a la crisis episcopal y a la situación sociopolítica de Arequipa. De esta manera, el prelado vinculó la defensa de la fe y la consolidación de la cultura católica en Arequipa con la preocupación «social redentora» de la religión, es decir, preocupada por los sectores sociales desfavorecidos. Por ello, volver la sociedad a Cristo era el lema de la nueva manera de entender la acción social católica en el espacio público. No bastaba confrontar, sino colaborar y transformar. Los laicos y laicas eran claves en esta estrategia episcopal y pontificia.

El obispo tuvo un destacado papel público en Arequipa y, hacia finales del régimen de Leguía, llegó a asumir la presidencia de manera interina. Su actividad pública se destacó por buscar soluciones a los problemas de la ciudad y vincularlos con el bien moral y religioso. Una de sus preocupaciones fue trasladar la prisión de mujeres a una sede más segura, pues la cárcel albergaba juntos a varones y mujeres en una situación deplorable para ellas. Tras algunas gestiones con el gobierno, se trasladó a las mujeres al local del antiguo Beaterio de la ciudad y se encargó a las franciscanas misioneras de María de «la reforma social de las asiladas» (Martínez 1933: 
312-313). ${ }^{22}$ La propuesta del prelado se ajustaba a los estándares reformistas de la sociología y los estudios penalistas de la época, y la hacía coincidir con la preocupación religiosa y moderna por la higiene y el orden. Por otra parte, a las mismas religiosas se les encargó el asilo correccional, el asilo de preservación, la escuela primaria externa, la escuela doméstica, el catecismo dominical, la comisaría para mujeres y la dirección de algunas congregaciones piadosas (Sáiz 1945: 58). Esta política episcopal mostraba la modernidad del programa del prelado. Moral católica y modernidad se conjugaban y coincidían para afrontar los retos de la Arequipa de inicios del siglo XX y mostraba la actualidad y relevancia de la Iglesia católica para responder a las exigencias de la ciudad.

La actividad pública del prelado adquirió también una dimensión abiertamente política cuando, en 1914, promovió el Partido Católico. El partido era una iniciativa de los laicos de la Unión Católica de Arequipa y el soporte del obispo lo hizo objetivo de una serie de ataques, a decir suyo: «con motivo de mi actuación en los trabajos políticos del partido católico de esta diócesis» (citado en Klaiber 1988: 124). En la instrucción pastoral para cuaresma de ese año, Holguín centró su reflexión sobre la defensa de la religión, no solo desde la apologética, sino desde el involucramiento activo de laicos en la política partidaria (1914: 3). La preocupación nacía de la aprobación parlamentaria de la tolerancia de cultos, que concluyó en la aprobación definitiva en noviembre de 1915 de la libertad religiosa (Armas 1998: 197-198). El prelado apelaba a la noción pontificia de «acción católica» como una forma de «fomentar la fe y defenderla de los ataques del error» y de «inyectar en el cuerpo social la savia divina de la moral del Evangelio». La «acción católica» era entendida como la labor apologética semejante a la del Apostolado de la Prensa, el cuidado de la moralidad pública, la

22 El Instituto de Religiosas Franciscanas Misioneras de María arribó al Perú el año de 1911, con la fundación de su primera casa en Arequipa (Sáiz 1945: 58). 
labor de «mejoramiento de la condición económica del pueblo» y el incremento de la piedad y la vida cristiana; pero, también, como la «actuación resuelta en la vida pública, en la política del país» (Holguín 1914: 3). De esta manera, la «acción católica» rompía la actitud intransigente respecto del mundo, para reconocerlo como un lugar necesitado de Dios. Para el prelado, el laico católico podría participar de las instituciones estatales para promover el progreso verdadero del país, desde la perspectiva de la fe. Un laico desentendido de la política se hacía partícipe de una «complicidad criminal; porque si son criminales los impíos que socavan los fundamentos del orden social, no lo son menos los que no oponen resistencia a su obra nefanda» (Holguín 1914: 3).

El obispo señalaba como obligación «en conciencia» de todo católico arequipeño la organización e inscripción en el Partido Católico del Perú. Se debía inscribir el partido en los registros nacionales y promover la inscripción de los laicos no solo en el Cercado de la ciudad, sino en todas las provincias de la diócesis. Para ello, facilitaba la estructura institucional de la diócesis de Arequipa. Además, el obispo resaltó la importancia del derecho a votar y la relación con los intereses del país; también destacó la obligatoriedad del voto y la militancia católica en el ejercicio del voto. De esta manera, el obispo reconocía el valor de la práctica electoral, del sistema político y de la pluralidad política. Esta actitud teológica era signo del proceso de modernización al interior del pensamiento y pastoral católicos en la primera mitad del siglo XX, en acuerdo con la apertura iniciada por León XIII y fortalecida por sus sucesores. Para el prelado era «deber ineludible de conciencia que todo católico y patriota, actuar en la Política del país con la mayor eficacia posible» (Holguín 1914: 4). Con ello, Holguín se mostraba a favor de una comprensión amplia de la noción de «acción católica» como participación de los laicos en la política partidaria para, con ello, obtener una representación política del catolicismo en los órganos de gobierno. La postura de Holguín implicaba el reconocimiento de la diversidad política en el 
contexto de cambios del país, aunque sin validarla — como se ha afirmado antes - como legítima.

Hacia finales de 1918, el nuncio apostólico en el Perú, monseñor Lorenzo Lauri, en contra de la postura del arzobispo de Lima Emilio Lissón, alentó a Holguín a coordinar y organizar el voto católico para las elecciones de 1919 (Ara 2012: 163). La proximidad de los candidatos, el civilista Antero Aspíllaga y el constitucionalista Augusto Leguía, con los liberales y protestantes, requería organizar el voto católico a través de un partido. No obstante el apoyo explícito del nuncio, Holguín reconocía en carta a Lauri del 4 de febrero de 1919 - previo a las elecciones - la dificultad para organizar el Partido Católico en Arequipa, que había entrado en receso, especialmente luego de que Lissón se declarase opuesto al mismo (Ara 2012: 157, nota 34). Las desavenencias de los obispos, en torno a la participación política católica a través de un partido, impidieron la consolidación del Partido Católico como un grupo activo en la vida política y pública del país. A diferencia de la apuesta episcopal en países como Chile, donde el Partido Conservador gozó durante la primera mitad del siglo XX del soporte de los obispos, en el Perú los obispos no lograron tener consenso sobre la situación política del Perú. Un año después, en 1919, el Partido Católico se encontraba abandonado y en total decadencia. Solo subsistió el modelo de asociación laical apologética y social en el espacio público. La politización de los laicos esperó hasta el posconcilio, pero marcado por la pluralidad de las opciones políticas y no por la elaboración de un programa político católico común.

Dentro de la política del monseñor Holguín de «compromiso» con la modernidad, no solo era central la entrada de los laicos en la política, sino también la promoción de la prensa católica como El Deber, fundada en 1890 como obra de la Unión Católica de Arequipa. Para ello, Holguín puso a disposición del periódico a sacerdotes y donó dinero para su sostenimiento. De igual forma, dotó con fondos a dos publicaciones católicas de Lima, primero La Unión y, 
a la desaparición de aquella, a La Tradición. Como parte de su compromiso con la prensa católica se suscribió a algunos periódicos extranjeros católicos con la finalidad de dar a conocer la realidad del catolicismo más allá del país. Muchos de esos periódicos se conservan hoy en La Recoleta. Holguín también promovió activamente la fundación, realizada en 1920, del periódico del Círculo de Obreros Católicos de la ciudad llamado La Colmena, así como a su sostenimiento (Martínez 1933: 314-315; Garreaud 2015, 3: 48). La preocupación por la prensa católica se vio justificada por la proliferación de publicaciones liberales y proclives al anarquismo y el socialismo como el periódico La Patria, cuyos redactores se mofaban del Deán Valdivia acusándolo de ser «un Cristo con pistolas»; de igual forma El Ariete, la revista Páginas Libres y La Voz del Sur, publicación en la que escribió Francisco Mostajo, destacado liberal y positivista arequipeño y abierto anticlerical.

En 1925, Holguín redactó una pastoral que manifestaba su activo compromiso patriótico con la protección de las provincias de Tacna y Arica, pertenecientes a la diócesis de Arequipa, y los sacerdotes expulsados por las autoridades chilenas. En la pastoral vinculaba la caridad cristiana con la exigencia de la justicia que, aplicada al plebiscito sobre Tacna y Arica, debía resolverse a favor del Perú. El reconocimiento por su compromiso lo expresó Gustavo Cornejo, vocal de la Corte Suprema, en un banquete en el Hotel Bolívar de Lima tras la reincorporación de Tacna y al que fue invitado el prelado arequipeño. En dicha ceremonia Cornejo subrayó el patriotismo del obispo en «esa hora suprema de la Patria» y la importancia de su patriótica pastoral. Destacó la presencia del obispo en la reincorporación de Tacna y en su visita a dicha ciudad, donde conmovió «a las muchedumbres hasta las lágrimas» y derramó «sobre ellas el bálsamo del consuelo» (citado en Martínez 1933: 317-318). Sin embargo, pasó a la historia como el único obispo presidente del Perú el 1 de marzo de 1931, aunque solo por unas horas, tras la caída del régimen de Leguía y la renuncia de Sánchez Cerro (Cabré 1959: 
210-214). También se desempeñó como Administrador Apostólico de la Arquidiócesis de Lima entre 1930 y 1933, después de la renuncia del arzobispo Emilio Lissón. Tras estos sucesos, la labor pastoral de Holguín se enfocó en las asociaciones católicas laicales, las que empezaron a asumir progresivamente los lineamientos pontificios. El 4 de octubre de 1925 Holguín respaldó la fundación de la Acción Social Católica, según las directrices del papa Pío XI de recristianizar las costumbres y la vida pública, de promover el reinado de Cristo en la sociedad y oponerse al laicismo ateo. De esta manera, la Acción Social Católica, nacida en 1925 en Arequipa, asumió progresivamente el criterio romano de la organización laical, dependiente y cercana a la autoridad jerárquica, pero más autónoma en la organización del movimiento laical y sus actividades. En esta empresa contó con la activa colaboración de Juan Gualberto Guevara, posteriormente arzobispo de Lima y primer cardenal del Perú, y del laico Juan Vidaurrazaga, fundador y dueño de La Ibérica (Martínez 1933: 314; Garreaud 2015, 3: 49).

Con la fundación de la Acción Social Católica, el monseñor Holguín se adelantó a la fundación nacional de la Acción Católica Peruana, ocurrida en Lima en el marco del Primer Congreso Eucarístico Nacional, en octubre de 1935. La Acción Católica de Arequipa se instaló oficialmente en 1935 y su primer logro institucional fue la organización del Segundo Congreso Eucarístico Nacional en Arequipa, en 1940, en cuya ocasión el papa Pío XII calificó a la ciudad como «La Roma del Perú». El título era el reconocimiento de la trayectoria católica de la ciudad desde mediados del siglo XIX. El reconocimiento pontificio se repitió el 23 de mayo de 1943, cuando Pío XII elevaba el obispado de Arequipa a la categoría de arquidiócesis y, con ello, el monseñor Holguín se convirtió en su primer arzobispo. Poseedor de una salud frágil, hacia finales de 1945, el presidente José Luis Bustamante envió a sus hermanos para solicitar a Holguín la aceptación de la sede de Lima, a causa de la muerte de Pedro Pascual Farfán, y como se sospechaba, la pro- 
moción al cardenalato. Sin embargo, Holguín rechazó la propuesta y, tras una larga agonía, falleció el 23 de diciembre de 1945 (Cabré 1959: 286-288).

CONCLUSIONES: CATOLICISMO ULTRAMONTANO Y MODERNIDAD DESDE UNA PERSPECTIVA REGIONAL

A partir del papel de los tres prelados estudiados, en el marco de modernización de Arequipa y de reconfiguración de la vida católica, se puede comprender desde una mirada local la recepción del ultramontanismo y el catolicismo social, así como las negociaciones con el contexto sociopolítico. Los tres obispos estuvieron en Roma, una ciudad-centro de la resistencia intelectual y emotiva contra los embistes de los múltiples «enemigos» de la fe. La experiencia romana afianzó la formación ultramontana de los tres clérigos y, como ocurrió a lo largo del siglo XIX con todos los visitantes de la Ciudad Eterna, probablemente se sintieron confirmados en la fe por su encuentro con el Romano Pontífice. La experiencia de la romanité, «la perfección de la catolicidad», era central en el compromiso ultramontano en la defensa de la Iglesia frente a sus enemigos, en la esfera pública, así como el reclamo de la autonomía administrativa respecto de las autoridades civiles. Sin embargo, la intransigencia de Pío IX menguó durante el pontificado de León XIII, quien — sin claudicar en la postura defensiva - abrió espacios para la participación pública de los católicos. Por ello, es posible ver las diferentes trayectorias entre los obispos de la sede arequipeña. Desde la dura intransigencia de Juan Ambrosio Huerta que ejemplifica una actitud política y espiritual hasta la apologética con compromiso social y político de Mariano Holguín. Ellos eran obispos pertenecientes al «nuevo catolicismo» gestado en la tensión y «compromiso» — entendido como negociación, acomodo, ambivalencia o rechazo total- con la modernidad. Por ejemplo, el rechazo de la soberanía del poder civil 
sobre la Iglesia se dio de diversas maneras — entre la intransigencia y el «compromiso»— como dan cuentan las pastorales de Huerta, la ceremonia de elevación de la cruz en el Misti de Ballón y el impulso dado al Partido Católico en Arequipa por parte de Holguín.

El ultramontanismo es imposible comprenderse sin el desafío de la modernidad. No obstante, en Arequipa la modernidad no tuvo un impacto disruptivo como en Europa o en otras partes de América Latina. Se destacan tres momentos de la relación entre ultramontanismo y modernidad en Arequipa. La primera durante el episcopado de Juan A. Huerta, quien era un férreo ultramontano y gran divulgador de las ideas doctrinales del papado. Su interés por la formación doctrinal y devocional de los presbíteros y los fieles se manifestaron en sus varias cartas pastorales. En ellas se encargó de otorgar rostros a los «enemigos del catolicismo» en el contexto del proceso de secularización institucional del país y del surgimiento de los primeros grupos liberales y protestantes. Sin comprender a profundidad el cambio de siglo que se avecinaba, buscó monopolizar el espacio público, a través de organizaciones laicales como la Unión Católica de Arequipa, fundada en 1886, y conservar la cuota de poder eclesial en el Estado, como demuestra la orden de prisión contra los protestantes en Arequipa en enero de 1889. Su sucesor, el obispo Manuel Ballón era un ultramontano fiero que comprendió la importancia de las asociaciones laicales para garantizar la presencia pública del catolicismo en el espacio público. Como Huerta, Ballón mantuvo una actitud intransigente frente a los nuevos actores políticos y religiosos de la ciudad y no logró comprender la situación social e ideológica de la ciudad. A pesar de que los aires teológicopolíticos habían empezado a cambiar con León XIII, la recepción de sus ideas realizada por Ballón se mantuvo en el plano intransigente. Su renuncia en 1905, ante la presión de los sectores liberales de Arequipa, cerraba un ciclo de un «compromiso» con la modernidad signada más por el rechazo ideológico-público que por la negociación. En este sentido, el obispo Mariano Holguín logró entender 
el «compromiso» como una apuesta compleja del catolicismo con la modernidad arequipeña. Durante su episcopado se consolidó en el espacio público el laicado militante, la prensa, las obras de caridad y educativas, las actividades entre los sectores trabajadores y la participación política de grupos de laicos. En este sentido, colaboró con el Estado como dan cuenta su pastoral a favor de Tacna y Arica y creía firmemente en la creación de un Partido Católico, como medio para hacer presente las ideas católicas en el debate público. Era un reconocimiento de la creciente pluralidad política del país, pero no una validación de todas las opciones políticas.

Finalmente, Holguín, como era ya reconocido desde los episcopados de Huerta y Ballón, consideraba que Arequipa era un baluarte de la fe católica en el país. Esta histórica ciudad era la garante doctrinal frente a la centralista y liberal Lima. En medio de este proceso histórico, en la «Roma del Perú», la Iglesia en su conjunto -obispos, clero y laicado— giró hacia el espacio público frente a la pérdida del poder civil en un Estado en proceso de secularización institucional y cada vez más centralizado. En este movimiento, la Iglesia de Arequipa, y con ella la del Perú, sentó las bases de la presencia del catolicismo en el espacio público como plataforma política y social que ha caracterizado, desde entonces, al catolicismo peruano del preconcilio y del posconcilio.

\section{REFERENCIAS}

\section{FUENTES PRIMARIAS}

1874 Memoria que el Ministro de Estado en el despacho de Instrucción, Culto, Justicia y Beneficencia presenta al Congreso Nacional de 1874 (Lima, julio 28 de 1874). Lima: Imprenta del Universo de Carlos Prince.

1888 iAl pueblo católico! El velo de la masonería descorrido hasta en lo más recóndito de sus secretos. Traducido de una obra francesa titulada $L a$ Masonería práctica, del Dr. D. R. de C. M. Arequipa: Imprenta de la Crónica Imparcial. 
1899 Carta Sinodal que los Arzobispos y Obispos congregados en Roma para el Concilio Plenario de la América Latina dirigen al Clero y los fieles de sus Diócesis. Arequipa: Tipografía Cáceres.

BALLón, Manuel Segundo

1883 Breve tratado de los principios filosóficos de moral. Arequipa: Imprenta de La Bolsa.

1898 Carta Pastoral que el Ilustrísimo y Reverendísimo Monseñor Manuel Segundo Ballón dirige al Clero y fieles de su Diócesis al tomar posesión de ella. Arequipa: Imprenta de La Bolsa.

1899a Carta Pastoral que el Ilustrísimo y Reverendísimo Monseñor Manuel Segundo Ballón dirige al Clero y fieles de su Diócesis con motivo del viaje que bace a Roma para tomar parte en el Concilio Plenario de la América Latina. 15 de marzo de 1899. Lima: Imprenta y Librería de San Pedro.

1899b Carta Pastoral que el Ilustrísimo y Reverendísimo Monseñor Manuel Segundo Ballón, obispo de Arequipa, dirige al Clero y fieles de su Diócesis, al regresar de Roma después del Primer Concilio Plenario de la América Latina. 3 de octubre de 1899. Arequipa: Imprenta de La Bolsa.

1899c Instrucción Pastoral que el Ilustrísimo y Reverendísimo Monseñor D. D. Manuel Segundo Ballón obispo de Arequipa dirige al Clero y fieles de sus Diócesis, con motivo del indulto apostólico del ayuno y abstinencia que Su Santidad el Papa León XIII ha concedido a los fieles de la América Latina. 30 de octubre de 1899. Arequipa: Tipografía Cáceres.

1900a Edicto, Instrucciones y Ceremonial de la Santa Visita de la Diócesis que el Ilustrísimo y Reverendísimo Señor Obispo Dr. D. Manuel Segundo Ballón iniciará en el presente año de 1900. 5 de septiembre de 1900. Arequipa: Imprenta de La Bolsa.

1900b Carta Pastoral que el Ilustrísimo y Reverendísimo señor obispo de Arequipa dirige al Clero y fieles de su Diócesis, probibiendo la lectura de publicaciones impias e inmorales. 24 de septiembre de 1900. Arequipa: Tipografía y Encuadernación Medina.

1900c Carta Pastoral que el Ilustrísimo y Reverendísimo señor obispo de Arequipa, D. D. Manuel Segundo Ballón, dirige al Clero y fieles de su Diócesis con motivo de la colocación de una gran cruz de bierro en la cima del Misti, en homenaje al divino Redentor del mundo, al terminar el siglo XIX. 8 de octubre de 1900. Arequipa: Imprenta de La Bolsa.

1901 Carta Pastoral que el Ilustrísimo y Reverendísimo Dr. D. Monseñor Manuel Segundo Ballón, obispo de Arequipa, dirige al Clero y fieles de su Diócesis, 
con motivo de la extensión del Jubileo del año santo a todo el orbe católico. 1 de mayo de 1901. Arequipa: Tipografía Muñiz.

1904 Carta pastoral que el Iltmo. y Rvmo. Señor Obispo de Arequipa, dirige al clero y fieles de su diócesis, sobre el matrimonio civil, en la cuaresma de 1904. Arequipa: Tipografía y encuadernación Medina.

El Deber

1900-1907

Holguín, Mariano

1914 Instrucción Pastoral. Sobre la defensa de la religión que el Iltmo. Obispo de Arequipa, Monseñor Fr. Mariano Holguin, O.F.M., dirige al clero y fieles de su Diócesis, con motivo de la Cuaresma. 2 de febrero de 1914. Arequipa.

HuerTA, Juan Ambrosio

1865 «Carta pastoral». En: F. Piérola. Anales de la Iglesia de Puno. Bajo el Gobierno Pastoral de su Dignísimo Obispo Fundador, el Ilustrísimo Señor Dr. D. Juan Ambrosio Huerta. Tomo 1 - 1865. Puno: Imprenta de «la Iglesia puneña», pp. 101-112.

1880 Carta pastoral que el Ilustrísimo Señor Obispo de Arequipa Dr. D. Juan Ambrosio Huerta dirige al Cabildo eclesiástico, clero y fieles de su Diócesis al tomar posesión de ella. Lima: Tipografía de La Sociedad.

1881 Carta pastoral que el Ilustrísimo Señor Obispo de Arequipa Dr. D. Juan Ambrosio Huerta dirige al Cabildo eclesiástico, clero y fieles de su Diócesis. Arequipa: Imprenta de San Agustín.

1883 «Carta pastoral». En: Constituciones sinodales del obispado de Arequipa dadas y promulgadas en el Sinodo Diocesano celebrado por su obispo propio el Ilustrísimo D. D. Juan Ambrosio Huerta, en los dias 31 de agosto y siguientes del mes de setiembre del año del Señor 1883. (pp. 9-14). Arequipa: Imprenta de La Bolsa.

1883 Constituciones sinodales del obispado de Arequipa dadas y promulgadas en el Sinodo Diocesano celebrado por su obispo propio el Ilustrísimo D. D. Juan Ambrosio Huerta, en los dias 31 de agosto y siguientes del mes de setiembre del año del Señor 1883. Arequipa: Imprenta de La Bolsa.

1886 Carta pastoral del Obispo de Arequipa Dr. D. Juan Ambrosio Huerta en que traza a los católicos de su Diócesis la conducta que tócales seguir en la lucha provocada por los masones del Perú. 15 de octubre de 1886. Arequipa: Imprenta de la Crónica Imparcial. 
1886a Instrucción Pastoral que el Obispo de la Diócesis Dr. D. Juan Ambrosio Huerta, dirige al Consejo Directivo y a todos los miembros de la «Unión Católica» de Arequipa. 15 de noviembre de 1886. Arequipa: Imprenta de la Crónica Imparcial.

1887 Carta pastoral que con motivo del jubileo sacerdotal de Nuestro Santísimo Padre el Papa León XIII, dirige a todos sus diocesanos el Obispo de Arequipa, Dr. D. Juan Ambrosio Huerta. Arequipa: Imprenta de la Crónica Imparcial.

1891 Carta pastoral que el Ilustrísimo Señor Obispo de Arequipa Dr. D. Juan Ambrosio Huerta dirige al clero y fieles de su Diócesis con motivo de la Enciclica de Nuestro S.S. Padre León XIII sobre el estado actual de los obreros. Lima: Tipografía Católica.

Passarell, Elías, O.F.M.

1886 La francmasonería peruana. Nueva edición. Arequipa: Imprenta de Ricardo B. Medina.

Unión Católica de ARequipa

1887 Exposición de la Unión Católica de Arequipa a sus conciudadanos. Arequipa: Tipografía Cáceres.

\section{FUENTES SECUNDARIAS}

ANDERSON, Margaret

2000 «The Divisions of the Pope: The Catholic Revival and Europe's Transition to Democracy». En: Austen Ivereigh (ed.). The Politics of Religion in an Age of Revival. Londres: ILAS; University of London, pp. 22-42.

Ara, Jesús

2012 «La Acción Católica y la política en el Perú: la posición de los prelados peruanos a principios de la década de 1920». Boletín Americanista, vol. LXII, núm. 65, pp. 147-166.

Armas, Fernando

1998 Liberales, protestantes y masones. Modernidad y tolerancia religiosa. Perú, siglo XIX. Lima: Pontificia Universidad Católica del Perú; Centro de Estudios Regionales Andinos «Bartolomé de Las Casas». 
BALLÓN, Héctor

2001 «Crisis de la autoridad eclesiástica y sus luchas con los liberales de la tercera generación y los protestantes. 1900-1940». Historia. Revista de la Escuela Profesional de Historia, Universidad Nacional San Agustín, núm. 4, pp. 155-165.

Benito, José Antonio

1998 «La Cruz del Misti». Hyeronymianun. Revista del Seminario San Jerónimo. Arquidiócesis de Arequipa, núm. 3, diciembre, pp. 40-47.

CABré, Francisco, O.F.M.

1959 Biografía del Excelentísimo y Reverendísimo Monseñor Fr. Mariano Holguin O.F.M. primer Arzobispo de Arequipa (Perú), 1869-1945. Lima: Editorial San Antonio.

CÁrdenas Ayala, Elisa

2018 Roma: el descubrimiento de América. México: El Colegio de México.

CARPIO, Juan Guillermo

1990 «La inserción de Arequipa en el desarrollo mundial del capitalismo (1867-1919)». En: Máximo Neira Avendaño, Guillermo Galdós Rodríguez, Alejandro Málaga Medina, Eusebio Quiroz Paz Soldán y Juan Guillermo Carpio Muñoz (eds.). Historia General de Arequipa. Arequipa: Fundación M. J. Bustamante de la Fuente, pp. 489-578.

Chadwick, Owen

1998 A History of the Popes 1830-1914. Oxford: Oxford University Press.

Clark, Christopher

2003 «The New Catholicism and the European culture wars». En: Christopher Clark y Wolfram Kaiser (eds.). Culture Wars. SecularCatholic Conflict in Nineteenth-Century Europe. Cambridge: Cambridge University Press, pp. 11-46.

FERNÁNDEZ, Enrique

2000 Perú cristiano. Primitiva evangelización de Iberoamérica y Filipinas, 14921600 e Historia de la Iglesia en el Perú, 1532-1900. Lima: Pontificia Universidad Católica del Perú. 
Flores Galindo, Alberto

1993 «Arequipa y el sur andino. Ensayo de historia regional. Siglos XVIII-XX». En: Alberto Flores Galindo. Obras completas I. Lima: SUR Casa de Estudios del Socialismo; Fundación Andina, pp. 231-454.

FONSECA, Juan

2002 Misioneros y civilizadores. Protestantismo y modernización en el Perú(19151930). Lima: Pontificia Universidad Católica del Perú.

FoullLoux, Étienne

1998 Une Église en quête de liberté: La pensée catholique française entre modernisme et Vatican II (1914-1962). París: Desclée de Brouwer.

Garreaud, Emilio

2015 Un siglo de solidaridad con el pobre. La acción social de la Iglesia en Arequipa. Volumen 3. Las gestas del clero y los consagrados en las tierras del Misti. San José: Universidad Juan Pablo II.

Hernández, Miguel-Ángel

2016 En defensa de los sagrados intereses. Historia religiosa de la diócesis de Zamora durante la Restauración (1875-1914). Salamanca: Universidad de Salamanca.

IANNETTONE, Giovanni (ed.)

2003 La Misión Herrera (1852): repertorio documental conmemorativo del CL aniversario. Lima: Asociación de Funcionarios del Servicio Diplomático del Perú.

IvereIgH, Austen (ed.)

2000 «The Politics of Religion in an Age of Revival». The Politics of Religion in an Age of Revival. Londres: ILAS, University of London, pp. 1-21.

IBERICO, Rolando

2013 La república católica dividida: ultramontanos y liberales-regalistas (Lima, 1855-1860). Tesis de licenciatura. Lima: Pontificia Universidad Católica del Perú. 
2015 «"La fe de todos los siglos”: una aproximación a la relación entre teología ultramontana e historiografía católica en el Perú». Cultura y Religión, vol. IX, núm. 1, pp. 9-33.

2017 La Roma del Perú: resurgimiento católico, espacio público y política en Arequipa (1860-1925). Tesis de maestría. Lima: Pontificia Universidad Católica del Perú.

JeDin, Hubert

1960 Breve historia de los concilios. Barcelona: Editorial Herder.

KLAIBER, Jeffrey

1988 La Iglesia en el Perú. Su historia social desde la independencia. Segunda edición. Lima: Pontificia Universidad Católica del Perú.

Kiarén, Peter

1992 «Los orígenes del Perú moderno, 1880-1930». En: Leslie Bethell (ed.). Historia de América Latina. 10. América del Sur, c. 1870-1930. Barcelona: Crítica, pp. 233-279.

MARTíneZ, Santiago

1933 La Diócesis de Arequipa y sus Obispos. Arequipa: Tipografía Cuadros.

SÁız, Odorico

1945 Reseña histórica y estado actual de la Provincia Misionera de San Francisco Solano del Perú. Con datos de la segunda y tercera orden franciscanas de ella dependientes o con ella relacionadas. Lima: Sanmartí y Cía.

TAYLOR, Charles

2014 La era secular. Tomo I. Barcelona: Editorial Gedisa.

WRight-Rios, Edward

2009 Revolutions in Mexican Catholicism. Reform and Revelation in Oaxaca, 1887-1934. Durham: Duke University Press.

Fecha de recepción: 17 de marzo de 2019.

Fecha de aceptación: 30 de septiembre de 2019.

Fecha de publicación: 1 de diciembre de 2020. 